\title{
Complement, infection, and autoimmunity
}

\author{
Paola Conigliaro a,*, Paola Triggianese ${ }^{\mathrm{a}, *}$, Eleonora Ballanti ${ }^{\mathrm{a}}$ \\ Carlo Perricone $^{\mathrm{b}}$, Roberto Perricone ${ }^{\mathrm{a}}$, and Maria Sole Chimenti ${ }^{\mathrm{a}}$
}

\begin{abstract}
Purpose of review
Complement system dysfunction in terms of upregulation, downregulation, or dysregulation can create an imbalance of both host defense and inflammatory response leading to autoimmunity. In this review, we aimed at describing the role of complement system in host defense to inflection and in autoimmunity starting from the evidence from primary and secondary complement system deficiencies.
\end{abstract}

\section{Recent findings}

Complement system has a determinant role in defense against infections: deficiencies of complement components are associated with increased susceptibility to infections. Primary complement system deficiencies are rare disorders that predispose to both infections and autoimmune diseases. Secondary complement system deficiencies are the result of the complement system activation with consumption. Complement system role in enhancing risk of infective diseases in secondary deficiencies has been demonstrated in patients affected by systemic autoimmune disorders, mainly systemic lupus erythematosus and vasculitis.

\section{Summary \\ The relationship between the complement system and autoimmunity appears paradoxical as both the deficiency and the activation contribute to inducing autoimmune diseases. In these conditions, the presence of complement deposition in affected tissues, decreased levels of complement proteins, and high levels of complement activation fragments in the blood and vessels have been documented.}

\section{Keywords}

autoimmunity, complement system, infections, primary deficiency

\section{INTRODUCTION}

Complement system plays an essential role in both innate and adaptive immune responses. A dysfunction in this system in terms of upregulation, downregulation, or dysregulation can cause a wide range of effects, including disturbance of normal host defense and altered inflammatory response [1]. Primary complement defects are included among immunodeficiency diseases and are characterized mainly by infections but also by autoimmune diseases [2]. Moreover, infections represent important triggering factors of autoimmune diseases. Therefore, a vicious circle is set up in which complement, infections, and autoimmunity represent actors with interconnected roles and mutual exchange of inputs in the scenario of human diseases (Fig. 1). Complement system can be activated through three pathways: the classical, the alternative and the lectin pathways. The activation process can be divided into three main phases: the first is the recognition step, with binding between different recognition molecules and foreign molecules on the microbial surface, turning on the complement 'engine'; the second phase is the formation of convertase enzymes that cleave the key proteins C3 and C5; the third step is the constitution of the membrane attack complex (MAC) leading to microorganism lysis [3]. A large variety of microorganisms have been recognized as target of mannan-binding lectin (MBL) of the lectin pathway, including gram-positive and gram-negative bacteria, viruses, fungi, and protozoa [4]. MAC specifically kills gram-negative bacteria. Gram-positive bacteria are protected from MAC-dependent lysis by their thick peptidoglycan

aDepartment of Systems Medicine, Rheumatology, Allergology and Clinical Immunology, University of Rome Tor Vergata and bipartimento Medicina Interna e Specialità Mediche, Lupus Clinic, Reumatologia, Sapienza Università di Roma, Rome, Italy

Correspondence to Roberto Perricone, Department of Systems Medicine, Rheumatology, Allergology and Clinical Immunology, University of Rome Tor Vergata, Viale Oxford 81, 00133 Rome, Italy.

Tel: +39 06 20900587; e-mail: roberto.perricone@uniroma2.it

*These authors contributed equally to the study.

Curr Opin Rheumatol 2019, 31:532-541

DOI:10.1097/BOR.0000000000000633 


\section{KEY POINTS}

- Complement system dysfunction creates an imbalance of both host defense and inflammatory response leading to autoimmunity.

- Deficiencies of complement components are associated with increased susceptibility to infections.

- Primary complement system deficiencies are rare disorders that predispose to both infections and autoimmune diseases.

- Secondary complement system deficiencies are a hallmark of autoimmune diseases as SLE and vasculitis. layer $\left[5^{*}, 6\right]$. The importance of the complement system in the defense against infections is supported by the observation that a deficiency of complement components is always associated with increased susceptibility to infections. Aim of this review is to describe the role of complement system in host defense to infection and in autoimmunity starting from the evidence from primary and secondary complement system deficiencies.

\section{PRIMARY COMPLEMIENT DEFICIENCY}

Primary deficiencies of complement components are rare disorders that predispose to infections and/or autoimmune diseases. They are classified into two main groups: integral component defects

\section{Apoptosis, Auto-antibodies and Immune complex formation}

\section{$\downarrow$}

Activation of CS

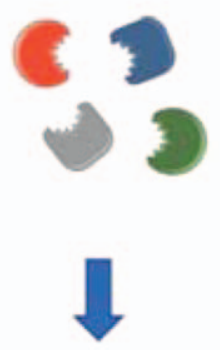

Consumption of CS

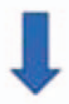

\section{Loss of Defence}

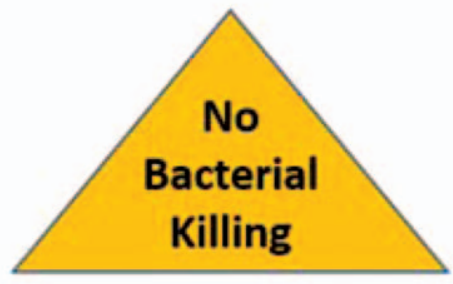

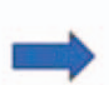

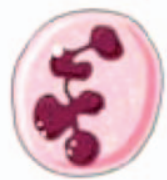

PMN cell
Inflammation and Immune cells recruitment
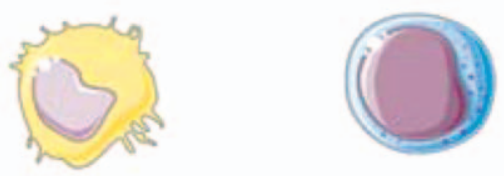

Macrophage

NK

\section{Endothelial cells activation}

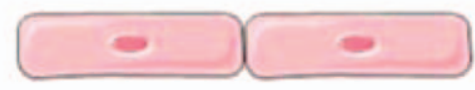

\section{Adaptive Immune cells activation}
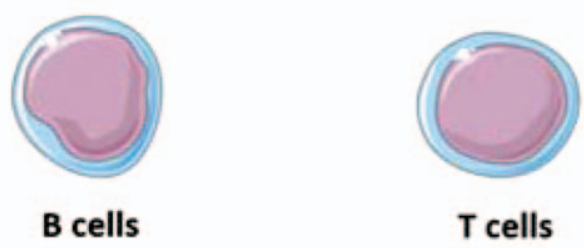

FIGURE 1. Complement system activation: linking host defense and autoimmunity. CS, Complement system; NK, natural killer; PMN, polymorphonuclear cells. 
and regulatory component defect $[1,2,7]$. Prevalence of primary complement deficiencies is difficult to establish as most deficiencies have a heterogeneous genetic background and that prevalence varies in different populations [8]. Screening of the general population for complement system deficiency in Western Countries and Japan has shown that this is a rare condition with an estimated frequency of approximately $0.03 \%$ [9]. Generally, most inherited disorders of the complement system leading to deficiency are autosomal recessive except for deficiency of C1-inhibitor protein (C1-INH), which is autosomal dominant, deficiency of properdin which is $\mathrm{X}$-linked recessive, and MBL and factor I deficiencies which are autosomal codominant [10].

\section{Primary complement deficiency and infections}

Main targets of complement activation are pyogenic organisms and neisserial microbes, but a role of complement proteins in the defense against viral infection has also been demonstrated. Increased susceptibility to infections occurs in patients with defects of complement proteins. Conversely, some organisms take advantage of the complement system to increase their virulence [11]. Recent findings support the hypothesis that some viruses and intracellular bacteria bind complement regulatory proteins and receptors as a means of escaping defense mechanisms [12].

Early, severe, bacterial infections in childhood suggest, among other possible causes, a complementary defect. Infections related to primary complement deficiencies can be distributed into two main categories: recurrent encapsulated bacterial infections (with or without rheumatic disorders) and recurrent Neisseria infections. Commonly, the defects that compromise the initial activation are associated with infections by encapsulated bacteria, such as Streptococcus pneumoniae and Haemophilus influenzae, conversely if the defect affects final components gram-negative infections, including Neisseria meningitidis and Neisseria gonorrhoeae infections, are observed [10]. Infections with meningococcal serogroups $\mathrm{W}-135$ and $\mathrm{Y}$ are particularly common in individuals with terminal complement deficiencies as well as in patients with properdin deficiency [10].

Low incidence of infection has been demonstrated in patients with C1q, C1r, C1s, and C4 deficiencies. Conversely, homozygous C2deficient individuals are often healthy but more susceptible to infections caused by encapsulated bacteria with onset of symptoms in early childhood $[13,14]$.
The frequency of MBL deficiency in the general white population has been estimated between 5 and $10 \%$. Most individuals with MBL deficiency genotype are healthy. However, children with low levels of MBL are at increased risk of infection with meningococcal agents. Adult MBL deficiency has been associated with susceptibility to many bacterial infections, particularly encapsulated bacteria, and with clinical severity of fungal, protozoal, and viral infections [15].

Differently from the defects of $\mathrm{C} 2$ and MBL, that often do not cause diseases, patients with primary C3 deficiency are particularly prone to infections with $S$. pneumoniae and Neisseria, which begin shortly after birth. H. influenzae can also be involved. Respiratory tract infections are prominent, including pneumonia, tonsillitis, sinusitis, and otitis [10]. Severe infections are characteristic in childhood. This emphasizes the key role of C3 as an opsonin for bacteria in early childhood, which is less crucial in adulthood, when protective antibodies responses have been developed $[1,2,7]$. Properdin deficiency is the only one of the early components of the alternative pathway for which more than a few cases have been reported. The disorder affects one-half of the males within the affected family because it is $\mathrm{X}$-linked [16]. Patients with properdin deficiency are highly susceptible to Neisserial infections. The risk of contracting meningococcal disease in deficient patients has been estimated to be 250 higher than that of the general population [17]. Course of the disease is often fulminant and is frequently complicated by sepsis. Patients with late complement component deficiencies are highly susceptible to Neisserial infections caused mainly by $N$. meningitidis. Risk of contracting meningococcal disease is 5-10000 higher in patients with late complement deficit [18]. Patients tend to have their first episode after age 10, are infected with an unusual serogroups (Y and $\mathrm{W}-135$ ) and to a lesser extent X. Interestingly, these infections tend to be recurrent and mild with a low mortality rate, unlike that seen in properdin deficiency suggesting a role of MAC in promoting complications of the disease [19].

\section{Primary complement deficiency and autoimmunity}

The relationship between the complement system and autoimmunity appears paradoxical as both the deficiency and the activation of complement system contribute to inducing autoimmune diseases [20]. A quite lacking clearance of immunocomplexes occurring in the presence of reduced levels of complement system components can cause an excess of circulating immunocomplex along with a high 
concentration of apoptotic cells with resultant inflammatory damage. Immunocomplexes trigger humoral immune responses leading to autoimmune mechanisms and tissue injury. Therefore, immunocomplex diseases can arise in complement deficiency disorders because of the abnormalities in complement system regulation and activation [21].

Genetic deficiency of early components of complement system can be related to the occurrence of autoimmune diseases (Table 1). Deficiency of C1q affects the classical complement system pathway, whereas deficiency of $\mathrm{C} 2$ and $\mathrm{C} 4$ also interfere with the lectin pathway. Thus, in the absence of $\mathrm{C} 2$ but not in absence of $\mathrm{C} 4$ or $\mathrm{C} 1 \mathrm{q}$, bypass mechanisms modulate complement system activation. Evidence reported that almost $40 \%$ of individuals with C2 deficiency (C2D), the most frequent hereditary deficiency in complement classical pathway, develop systemic autoimmune disease, particularly systemic lupus erythematosus (SLE), whereas 60\% of individuals C2D do not suffer from any apparent disease, probably because of the compensatory mechanisms $\left[22,23^{\prime \prime}, 24^{\prime \prime}\right]$.

Genes of complements C2 and C4 isotypes are closely located within the human leukocyte antigen (HLA) region and the relationship between complement deficiencies and immunocomplex diseases can be linked to the association with other HLA

Table 1. Main defects in complement system pathways and regulators: associated immune-mediated diseases

\begin{tabular}{|c|c|c|}
\hline Component & Genetic locus & Immune-mediated diseases \\
\hline \multicolumn{3}{|c|}{ Classical pathway deficiencies } \\
\hline $\mathrm{Clq}$ & $1 \mathrm{p} 36.12(\mathrm{~A}, \mathrm{~B}) 1 \mathrm{p} 36.11(\mathrm{C})$ & IC diseases, SLE, HUVS \\
\hline $\mathrm{Clr}$ and $\mathrm{Cls}$ & $12 \mathrm{p} 13$ & $\begin{array}{l}\text { IC diseases, SLE, GNP, chronic } \\
\text { immune thrombocytopenia }\end{array}$ \\
\hline $\mathrm{C} 4$ & $6 p 21.3$ & $\begin{array}{l}\text { SLE or lupus-like, IC diseases, type } \\
1 \text { diabetes mellitus, primary } \\
\text { biliary cirrhosis }\end{array}$ \\
\hline $\mathrm{C} 2$ & $6 p 21.3$ & SLE or lupus-like \\
\hline $\mathrm{C} 3$ & 19p13.3-p13.2 & IC diseases, HUS, GNP \\
\hline \multicolumn{3}{|c|}{ Lectin pathway deficiencies } \\
\hline$M B L$ & $10 q 11.2-q 21$ & SLE or lupus-like, RF/RHD, PE \\
\hline Ficolins $(M, L)$ & $9 q 34$ & $\mathrm{RF} / \mathrm{RHD}, \mathrm{PE}$ \\
\hline $\mathrm{H}$ ficolin & $1 p 36.11$ & PE \\
\hline MASPs & $3 q 27-q 28(1), 1 p 36.3-p 36.2$ (2) & $\mathrm{RF} / \mathrm{RHD}$ \\
\hline \multicolumn{3}{|c|}{ Alternative pathway deficiencies } \\
\hline Properdin & Xp $11.3-p 11.23$ & - \\
\hline Factor B & $6 p 21.3$ & HUS, GNP \\
\hline Factor D & $19 p 13.3$ & - \\
\hline \multicolumn{3}{|c|}{ Terminal pathway deficiencies } \\
\hline $\begin{array}{l}\text { C5, C6, C7, C8, } \\
\text { and C9 }\end{array}$ & $\begin{array}{l}9 q 33-q 34(C 5), 5 p 13(C 6, C 7) \\
1 p 32, \text { and } 9 q 34.3(C 8), \\
5 p 14-p 12 \text { (C9) }\end{array}$ & $\begin{array}{l}\text { SLE or lupus-like disease, IC } \\
\text { diseases, ANCA-associated } \\
\text { vasculitis, APS, myasthenia } \\
\text { gravis, thrombotic } \\
\text { microangiopathy }\end{array}$ \\
\hline \multicolumn{3}{|c|}{ Regulatory component defect } \\
\hline CI-INH & SERPING 1 & $\mathrm{HAE}, \mathrm{AAE}, \mathrm{SLE}$ \\
\hline Factor $\mathrm{H}$ & lq31.3 & ITP, GNP, HUS \\
\hline CD59 & $11 \mathrm{p} 13$ & $\mathrm{PNH}$ \\
\hline CD46 & lq32.2 & HUS \\
\hline CR1 (CD35) & $1 q 32.2$ & IC diseases, GNP \\
\hline CR2 (CD21) & $1 q 32.2$ & CVID \\
\hline CR3 (CD18) & $21 q 22.3$ & Leukocyte adhesion deficiency \\
\hline
\end{tabular}

AAE, Acquired angioedema; ANCA, antineutrophil cytoplasmic antibody; APS, antiphospholipid syndrome; CVID, common variable immunodeficiency; GNP, glomerulonephritis; HAE, hereditary angioedema; HUS, hemolytic uremic syndrome; HUVS, hypocomplementemic urticarial vasculitis; IC, immunocomplex; ITP, immune thrombocytopenia; PE, preeclampsia; PNH, paroxysmal nocturnal hemoglobinuria; RF, rheumatic fever; RHD, rheumatic heart disease; SLE, systemic lupus erythematosus. 
disease susceptibility genes [22]. C4 is encoded by two genes: C4A and C4B on human chromosome $6 \mathrm{p}$ in the major histocompatibility complex. Complete deficiencies of complement components $\mathrm{C} 4 \mathrm{~A}$ and C4B represent genetic risk factors for SLE or lupuslike disease that depend on racial and genetic backgrounds [25]. C4 deficiency is also associated with autoimmune disorders that are not characterized by abnormalities of immunocomplex clearance (e.g., type 1 diabetes mellitus, primary biliary cirrhosis) [22].

Among complement proteins, a primary role in clearance activity is attributed to C1q. Although complete C1q deficiency is less frequent, that condition is associated with a higher prevalence with SLE. In mice with experimental C1q deficiency, the expression of autoimmune disease is strongly influenced by the genetic background [26]. SLE-like diseases have been associated also with late-complement component deficiencies (MAC components, C5, C6, C7, C8, and C9) [22].

Innate immune disturbances may be responsible for adverse pregnancy outcomes [27,28]. Studies demonstrated associations between MBL deficiency and immune-mediated inflammatory conditions including pregnancy syndrome such as preeclampsia $\left[29^{-}, 30\right]$. Furthermore, MBL deficiency has been associated per se with several autoimmune diseases including SLE and inflammatory arthritis [31].

In the context of deficiencies in complement system components, abnormalities in the regulators also have been associated with autoimmunity. Hereditary angioedema (HAE) because of deficiency of C1-INH is associated with enhanced consumption of the early complement system components that could affect immunocomplex clearance allowing autoimmunity. HAE patients have been reported to show an enhanced production of autoantibodies likely related also to an increased activation of B cells [32]. Some patients with HAE exhibit immunological abnormalities including anticardiolipin autoantibodies [33], C1-INH autoantibodies [34], thyroid autoimmunity [35], and in a minimum percentage defined systemic autoimmune diseases [36]. In this view, we might assume that in HAE the levels of complement components although reduced can be sufficient to avoid the immunocomplex precipitation: thus, the chance of autoimmunity can be not increased.

Moreover, mutations in the regulatory proteins factor $\mathrm{I}$ and $\mathrm{H}$ result in secondary $\mathrm{C} 3$ deficiencies [37]. As C3 is the major complement component and participates in all three pathways of activation, C3 deficiencies are associated in some cases with autoimmune diseases such as SLE. C3 deficiency is due to gain-of-function mutation in the C3 gene is recently described in vasculitis patients with persistently low levels of C3 and normal C4 [38]. The impact of complement dysregulation in the presence of abnormal activity of regulators factor $\mathrm{H}$, factor I, CD46, and factor B have been described in atypical hemolytic uremic syndrome (aHUS) [39], paroxysmal nocturnal hemoglobinuria (PNH) [40], and C3 glomerulopathies (membranoproliferative glomerulonephritis) [22]. Homozygous mutations in the complement factor I gene was identified as monogenic cause of small vessels vasculitis arising from immunocomplex deposition, resulting in complete absence of alternative pathway activity, decreased classical complement system activity, with low levels of serum factor I, C3, and factor $\mathrm{H}$ and normal C4 [41,42]. Dysregulation of complement system because of factor $\mathrm{H}$ defects is increasingly documented to be associated with renal diseases with a wide range of clinical and pathological patterns [43].

Complement regulators such as complement receptor type 1 and 2 exert a key role in B-cell receptor-induced proliferation and also on differentiation of B cells to plasmablasts and their immunoglobulin production. Reduced expression of complement receptor type 1 and type 2 on the $\mathrm{B}$ cells of patients with SLE and rheumatoid arthritis has been described $[44,22]$.

\section{SECONDARY COMPLEMENT DEFICIENCY}

Secondary complement deficiencies are relatively common. Any pathologic process that results in activation of the complement cascade may cause complement system consumption. The role of complement system in enhancing infective diseases in secondary complement deficiencies was mainly demonstrated in patients affected by autoimmune diseases.

\section{Secondary complement deficiency and autoimmunity}

The association between complement deficiency and SLE appears paradoxical: complement deficiency causes SLE, and yet SLE causes activation and consumption of complement components. Complement system is involved in both the early and late stages of disease development and organ damage. These observations suggest that the early part of the classical pathway plays a protective role against the development of SLE, whereas central and terminal component can contribute to disease development. Deficiency of classical pathway components displays a hierarchical association with the development of SLE. Individuals with deficiency of 
C1q have the highest prevalence of SLE and the most severe manifestations of the disease [45-47]. C1q may influence the immune response to selfantigens contained within the surface blebs generated by apoptotic cells [48]. Apoptotic DNA is normally opsonized by systemic immunoglobulin $\mathrm{M}$ (IgM), C1q, and early complement activation products $\mathrm{C} 4$ and $\mathrm{C} 2$. This opsonized debris is removed by tissue macrophages; therefore, organs are protected from its pathological accumulation. Inefficient local and systemic removal may result in increased levels of opsonized debris in the circulation. Altered function of complement receptors has been proposed to be responsible for the development of anti-dsDNA antibodies [49]. In addition, autoantibodies to C1q develop as part of the autoantibody response [50]. In SLE, they were detected in $28-60 \%$ of cases. AntiC1q antibodies are associated with proliferative lupus nephritis [51,52]. Their absence carries a negative predictive value for development of lupus nephritis of close to 100\% [53]. Anti-C1q in combination with anti-dsDNA and low complement has the strongest serological association with renal involvement [54]. The anti-C1q titers correlate with global disease activity scores in patients with renal involvement, and higher titers seem to precede renal flares [55-57]. After treatment-induced remission of a renal flare, anti-C1q has the tendency to decrease or even become undetectable [56]. Anti-C1q antibodies are detected in all patients with hypocomplementemic urticarial vasculitis but also in systemic sclerosis (26\%), rheumatoid arthritis (19\%), undifferentiated connective tissue disease (15\%), and Sjögren syndrome (14\%) [54].

Complement system is also implicated in the effector inflammatory phase of the autoimmune response that characterizes SLE [58-60]. Complement proteins are deposited in inflamed tissues causing consumption of complement [61]. Circulating immunocomplexes reach lymphoid organs and trigger the production of antigen-specific antibodies [62]. Immunoglobulin G (IgG), IgM, and C4 content of immunocomplexes may influence tissue deposition preference such as the kidney glomeruli causing tissue damage with lupus nephritis [63"',64]. Also during SLE disease flares, the complement system is activated giving rise to partial deficiency or dysfunction because of consumption [65].

Acquired C1-INH deficiency with consequent recurrent angioedema is a rare condition identified as acquired angioedema (AAE). The defect is caused by increased catabolism, which is often associated with the presence of serum autoantibodies against C1-INH [66]. Unlike those with HAE, AAE patients have no family history of angioedema and are characterized by the late onset of symptoms. The reduction in C1-INH function leads to activation of the complement system pathways and complement consumption, as well as activation of the contact system leading to the generation of the vasoactive peptide bradykinin, increased vascular permeability, and angioedema [67].

Complement system has an established role in antineutrophil cytoplasmic antibody (ANCA)-associated vasculitis (AAV) [68"']. Evidence from animal models and clinical observations revealed that alternative pathway is activated and the production of C5a is crucial. Stimulation of neutrophils with C5a and ANCA results in neutrophil degranulation and activation of the coagulative system pathways [69]. Biopsy samples of involved tissue showed a certain degree of immunocomplex and complement C3c deposition that was associated with proteinuria and poor renal function [70-72]. Similar results were found in other studies that analyzed renal biopsy samples from patients with ANCA-associated pauciimmune glomerulonephritis (GNP) and detected deposition of C3c, C3d, C4d, and C5b-9 in the majority of specimens, whereas hypocomplementia is rare in patients [73]. Plasma and urinary levels of complement fragments are increased during the flare of disease suggesting an important role in the pathogenesis $[74,75]$. The first evidence of the role of complement activation in the pathogenesis of AAV was provided by the mouse model of myeloperoxidase (MPO)-ANCA vasculitis [76]. C5-deficient mice or wild-type mice pretreated with cobra venom factor to deplete complement, failed to develop GNP and vasculitis. Furthermore, pretreatment with anti-C5 antibodies to block C5 prior to administration of anti-MPO IgG could also prevent the development of ANCA-associated GNP in mice [77]. Therefore, targeting complement components such as C5a might be an interesting strategy in these diseases. As activation of complement contributes to disease activity in complement-mediated diseases as SLE, monoclonal antibody against C5 (eculizumab) has been tested in murine models of SLE [78]. Promising results were obtained in small cohorts of SLE patients with refractory lupus nephritis and concomitant thrombotic microangiopathy (TMA) $[79,80]$. TMA is a life-threatening, infrequent, complication of SLE and antiphospholipid syndrome (APS). Complement activation plays a key role in the pathogenesis of secondary TMA because of SLE and APS; therefore, a therapy that targets the complement pathway is an attractive intervention (Table 2). Several studies have demonstrated the therapeutic efficacy of eculizumab in PNH and aHUS [81-83], leading to Food and Drug Administration approval for these indications. Small studies have assessed the use of eculizumab in other renal 
Table 2. Studies on treatments targeting complement system in autoimmune diseases

\begin{tabular}{|c|c|c|c|}
\hline Clinical trials & $\begin{array}{l}\text { Design and phase } \\
\text { (identifier) }\end{array}$ & $\begin{array}{l}\text { Autoimmune } \\
\text { conditions }\end{array}$ & $\begin{array}{l}\text { Complement system- } \\
\text { targeted treatment }\end{array}$ \\
\hline $\begin{array}{l}\text { Efficacy and Safety of LNPO23 in } \\
\text { Primary IgA Nephropathy Patients }\end{array}$ & $\begin{array}{l}\text { Interventional randomized, } \\
\text { parallel assignment, phase } \\
2 \text { (NCT03373461) }\end{array}$ & $\begin{array}{l}\text { Primary } \lg \mathrm{A} \\
\text { nephropathy }\end{array}$ & $\begin{array}{l}\text { LNP023: factor B inhibitor, } \\
\text { small molecule }\end{array}$ \\
\hline $\begin{array}{l}\text { CCX168 (Avacopan) in Patients with } \\
\text { ANCA-Associated Vasculitis } \\
\text { (ADVOCATE) }\end{array}$ & $\begin{array}{l}\text { Interventional randomized, } \\
\text { parallel assignment, phase } \\
3 \text { (NCT02994927) }\end{array}$ & ANCA vasculitis & $\begin{array}{l}\text { CCX168: C5aR inhibitor, } \\
\text { small molecule }\end{array}$ \\
\hline $\begin{array}{l}\text { Controlled Trial Evaluating Avacopan } \\
\text { in C3 Glomerulopathy }\end{array}$ & $\begin{array}{l}\text { Interventional randomized, } \\
\text { parallel assignment, phase } \\
2 \text { (NCT03301467) }\end{array}$ & C3 GNP & $\begin{array}{l}\text { CCX168: C5aR inhibitor, } \\
\text { small molecule }\end{array}$ \\
\hline BIVV009 in Participants with ITP & $\begin{array}{l}\text { Interventional, single group } \\
\text { assignment, phase } 1 \\
\text { (NCT03275454) }\end{array}$ & ITP & $\begin{array}{l}\text { BIVV009: } \mathrm{Cls} \text { inhibitor, } \\
\text { humanized mAb }\end{array}$ \\
\hline $\begin{array}{l}\text { C1-Esterase Inhibitor (Cinryze) for } \\
\text { Acute Treatment of Neuromyelitis } \\
\text { Optica Exacerbation }\end{array}$ & $\begin{array}{l}\text { Interventional, single group } \\
\text { assignment, phase } 1 \\
\text { (NCT01759602) }\end{array}$ & Neuromyelitis optica & $\mathrm{Cl}$ esterase inhibitor, human \\
\hline $\begin{array}{l}\text { Terminal Complement Inhibition in } \\
\text { Patients with CCAD Using } \\
\text { Eculizumab }\end{array}$ & $\begin{array}{l}\text { Interventional, single group } \\
\text { assignment, phase } 2 \\
\text { (NCT01303952) }\end{array}$ & CCAD & $\begin{array}{l}\text { Eculizumab: } \mathrm{C} 5 \text { inhibitor, } \\
\text { humanized } \mathrm{mAb}\end{array}$ \\
\hline $\begin{array}{l}\text { BIVV009 in Healthy Volunteers and } \\
\text { Patients with Complement } \\
\text { Mediated Disorders (BIVV009-01) }\end{array}$ & $\begin{array}{l}\text { Interventional randomized, } \\
\text { parallel assignment, phase } \\
1 \text { (NCT02502903) }\end{array}$ & $\begin{array}{l}\mathrm{BP}, \mathrm{CCAD} \text {, warm } \\
\text { AHA }\end{array}$ & $\begin{array}{l}\text { BIVV009: } \mathrm{Cls} \text { inhibitor, } \\
\text { humanized mAb }\end{array}$ \\
\hline $\begin{array}{l}\text { Clinical Trial to Evaluate Safety and } \\
\text { Efficacy of CCX168 in ANCA- } \\
\text { Associated Vasculitis }\end{array}$ & $\begin{array}{l}\text { Interventional randomized, } \\
\text { parallel assignment, phase } \\
2 \text { (NCT02222155) }\end{array}$ & ANCA vasculitis & $\begin{array}{l}\text { CCX168: C5aR inhibitor, } \\
\text { small molecule }\end{array}$ \\
\hline $\begin{array}{l}\text { An Open Label Study of the Effects of } \\
\text { Eculizumab in Neuromyelitis } \\
\text { Optica }\end{array}$ & $\begin{array}{l}\text { Interventional, single group } \\
\text { assignment, phase } 2 \\
\text { (NCT00904826) }\end{array}$ & Neuromyelitis optica & $\begin{array}{l}\text { Eculizumab: } \mathrm{C} 5 \text { inhibitor, } \\
\text { humanized } \mathrm{mAb}\end{array}$ \\
\hline $\begin{array}{l}\text { Safety and Efficacy of Eculizumab in } \\
\text { Refractory Generalized Myasthenia } \\
\text { Gravis }\end{array}$ & $\begin{array}{l}\text { Interventional randomized, } \\
\text { parallel assignment, phase } \\
3 \text { (NCT01997229) }\end{array}$ & Myasthenia gravis & $\begin{array}{l}\text { Eculizumab: } \mathrm{C} 5 \text { inhibitor, } \\
\text { humanized } \mathrm{mAb}\end{array}$ \\
\hline $\begin{array}{l}\text { ALXN1210 in Children and } \\
\text { Adolescents with Atypical } \\
\text { Hemolytic Uremic Syndrome }\end{array}$ & $\begin{array}{l}\text { Interventional, single group } \\
\text { assignment, phase } 3 \\
\text { (NCT03131219) }\end{array}$ & Atypical HUS & $\begin{array}{l}\text { Ravulizumab: } \mathrm{C} 5 \text { inhibitor, } \\
\text { humanized } \mathrm{mAb}\end{array}$ \\
\hline $\begin{array}{l}\text { Eculizumab to Enable Renal } \\
\text { Transplantation in Patients with } \\
\text { History of Catastrophic APS }\end{array}$ & $\begin{array}{l}\text { Interventional, single group } \\
\text { assignment, phase } 2 \\
\text { (NCT01029587) }\end{array}$ & Catastrophic APS & $\begin{array}{l}\text { Eculizumab: } \mathrm{C} 5 \text { inhibitor, } \\
\text { humanized } \mathrm{mAb}\end{array}$ \\
\hline $\begin{array}{l}\text { Safety and Efficacy of Eculizumab in } \\
\text { Patients with Relapsing } \\
\text { Neuromyelitis Optica }\end{array}$ & $\begin{array}{l}\text { Interventional, single group } \\
\text { assignment, phase } 3 \\
\text { (NCT02003 144) }\end{array}$ & Neuromyelitis optica & $\begin{array}{l}\text { Eculizumab: } \mathrm{C} 5 \text { inhibitor, } \\
\text { humanized } \mathrm{mAb}\end{array}$ \\
\hline
\end{tabular}

AHA, Autoimmune hemolytic anemia; ANCA, antineutrophil cytoplasmic antibody; BP, bullous pemphigoid; C5aR, C5a receptor; CCAD, chronic cold agglutinin disease; GNP, glomerulonephritis; HUS, hemolytic uremic syndrome; APS, antiphospholipid antibody syndrome; IgA, Immunoglobulin A; ITP, chronic immune thrombocytopenia; $\mathrm{mAb}$, monoclonal antibody.

diseases, including C3 GNP, immunoglobulin A nephropathy, but no reports have yet been published regarding the use of eculizumab in patients with AAV [84-86] (Table 2).

\section{Secondary complement deficiency and infections}

The most common bacterial infections in SLE patients, even in those who are on immunosuppressive medications, are the same infections and pathogens seen in general population: S. pneumoniae respiratory tract infections, Escherichia coli urinary tract infections, and Staphylococcus aureus skin and soft-tissue infections [87]. Herpes zoster is the most common viral pathogen in patients with lupus with rates higher than reported in age-matched populations with a particular risk for SLE patients on cyclophosphamide and azathioprine, and patients on more than $60 \mathrm{mg}$ daily of prednisone are at higher risk for bacterial suprainfection [88]. Over 90\% of patients with SLE are seropositive for cytomegalovirus as compared with $60-70 \%$ of the general population [89]. Women with SLE have a high prevalence of human papillomavirus and triple the prevalence of an abnormal pap smear as compared with healthy 
controls [90]. Fungal infections are rare and include Candida species, Pneumocystis jirovecii, and Cryoptococcus neoformas [91]. Infections are one of the major causes of mortality and of hospitalization in patients affected by SLE [92]. They represent one of the three major causes of death, along with renal and cardiovascular diseases [93]. Immunosuppressive therapies including glucocorticoids are associated with the risk of infections as well as the presence of lymphopenia and hypocomplementemia, but severe organ involvement such as lupus nephritis is also a major risk factor. In particular, acquired deficiency of the early components of the complement system $(\mathrm{C} 1 \mathrm{q}, \mathrm{C} 4$, and $\mathrm{C} 2)$ predisposes SLE patients to infections by encapsulated organisms [19]. Decreased levels of complement receptors 1 and 2 have been reported on B cells, polymorphonuclear cells, and red blood cells in patients with SLE enhancing infective risk [94].

Differentiating bacterial infection from disease relapse in SLE is a challenge for rheumatologist if based on clinical features alone because the clinical signs and symptoms of bacterial infection are similar to those of recurrent SLE patients such as fever, malaise, joint pain and myalgia [91]. Several biomarkers have been employed to identify bacterial infection. For instance, the levels of C-reactive protein (CRP), procalcitonin (PCT), white blood cell count (WBC) and erythrocyte sedimentation rate would increase during bacterial infection. However, the sensitivity and specificity of each of the above biomarkers alone is low [95]. Meanwhile, these levels would misleadingly be reduced in SLE patients with bacterial infection who are treated with immunosuppressants. Used as biomarkers of conventional disease activity, complement C3 and C4 may play a role in the progress of bacterial infection, but the mechanism for this role is not known. It has been demonstrated that serum levels of C3 and C4 were similar in infected and noninfected SLE patients [96"]. Feng et al. [97] explored the diagnostic role of C3, C4, CRP, PCT, WBC, neutrophil CD64 (nCD64) index, lymphocyte subsets, and their combination in differentiating bacterial infection from disease relapse in SLE. They set up a bioscore system to evaluate the significance of these biomarkers in identifying bacterial infection and disease relapse. The combination of nCD64 index, C3, C4, CRP, $\mathrm{WBC}$ and $\mathrm{B}$ cells in a bioscore resulted more valuable to monitor bacterial infection in SLE and may have more reference value for physicians to differentiate bacterial infection from disease relapse in SLE.

\section{CONCLUSION}

Primary complement defects increase the susceptibility to infections but also to autoimmune diseases.
Immunodeficiency disease and autoimmune disease, far to be separated entities, share a deep dysregulation of the complement system [7]. The presence of one of the two conditions does not exclude the other and overlapping symptoms are often observed. Infections related to primary complement deficiencies compose recurrent encapsulated bacterial infections and Neisseria infections. The evidence of the link between complement activation and autoimmune diseases characterizes secondary complement deficiency. This includes the presence of complement deposition in affected tissues, decreased levels of complement proteins and high levels of complement activation fragments in the blood, urine, and/or synovial fluid of patients $\left[98^{-*}, 99,100\right]$. Secondary complement deficiencies are characterized by an increased risk of infections, hospitalization, and increased morbidity also due to immunosuppressive medications.

\section{Acknowledgements}

None.

\section{Financial support and sponsorship}

None.

\section{Conflicts of interest}

There are no conflicts of interest.

\section{REFERENCES AND RECOMIMENDED}

\section{READINC}

Papers of particular interest, published within the annual period of review, have been highlighted as:

- of special interest

-1 of outstanding interest

1. Botto $M$, Kirschfink $M$, Macor $P$, et al. Complement in human diseases: lessons from complement deficiencies. Mol Immunol 2009; 46:2774-2783.

2. Picard $\mathrm{C}, \mathrm{Al}-\mathrm{Herz} \mathrm{W}$, Bousfiha $\mathrm{A}$, et al. Primary immunodeficiency diseases: an update on the classification from the international union of immunological societies expert committee for primary immunodeficiency 2015. J Clin Immunol 2015; 35:696.

3. Rus H, Cudrici C, Niculescu F. The role of the complement system in innate immunity. Immunol Res 2005; 33:103-112.

4. Kjaer TR, Thiel S, Andersen GR. Toward a structure-based comprehension of the lectin pathway of complement. Mol Immunol 2013; 56:413-422.

5. Heesterbeek DA, Angelier ML, Harrison RA, Rooijakkers SH. Complement

- and bacterial infections: from molecular mechanisms to therapeutic applications. J Innate Immun 2018; 10:455-464.

This review dissects the interplay between complement and bacteria.

6. Berends ET, Dekkers JF, Nijland R, et al. Distinct localization of the complement C5b-9 complex on Gram-positive bacteria. Cell Microbiol 2013; 15:1955-1968.

7. Grammatikos AP, Tsokos GC. Immunodeficiency and autoimmunity: lessons from systemic lupus erythematosus. Trends Mol Med 2012; 18:101-108.

8. Sjöholm AG, Jönsson G, Braconier JH, et al. Complement deficiency and disease: an update. Mol Immunol 2006; 43:78-85.

9. Tedesco F. Inherited complement deficiencies and bacterial infections. Vaccine 2008; 8:13-18.

10. Pettigrew HD, Teuber SS, Gershwin ME. Clinical significance of complement deficiencies. Ann NY Acad Sci 2009; 1173:108-123.

11. Walport MJ. Complement: first of two parts. N Engl J Med 2001; 344 : $1058-1066$.

12. Lindahl G, Sjobring U, Johnsson E. Human complement regulators: a major target for pathogenic microorganisms. Curr Opin Immunol 2000; 12:44-51. 
13. Ram S, Lewis LA, Rice PA. Infection of people with complement deficiencies and patients who have undergone splenectomy. Clin Microbiol Rev 2010; 23:740-780

14. Jönsson G, Truedsson L, Sturfelt G, et al. Hereditary C2 deficiency in Sweden: frequent occurrence of invasive infection, atherosclerosis, and rheumatic disease. Medicine (Baltimore) 2005; 84:23-34.

15. Neth O, Hann I, Turner MW, Klein NJ. Deficiency of mannose-binding lectin and burden of infection in children with malignancy: a prospective study. Lancet 2001; 358:614-618.

16. Späth PJ, Sjöholm AG, Fredrikson GN, et al. Properdin deficiency in a large Swiss family: identification of a stop codon in the properdin gene, and association of meningococcal disease with lack of the lgG2 allotype marker G2m(n). Clin Exp Immunol 1999; 118:278-284.

17. Fijen CA, Kuijper EJ, te Bulte MT, et al. Assessment of complement deficiency in patients with meningococcal disease in The Netherlands. Clin Infect Dis 1999; 28:98-105.

18. Overturf GD. Indications for the immunological evaluation of patients with meningitis. Clin Infect Dis 2003; 36:189-194.

19. Ross SC, Densen P. Complement deficiency states and infection: epidemiology, pathogenesis and consequences of neisserial and other infections in an immune deficiency. Medicine (Baltimore) 1984; 63:243-273.

20. Triggianese $P$, Chimenti MS, Toubi $E$, et al. The autoimmune side of hereditary angioedema: insights on the pathogenesis. Autoimmun Rev $2015 ; 14: 665-669$

21. Lewis MJ, Botto M. Complement deficiencies in humans and animals: links to autoimmunity. Autoimmunity 2006; 39:367-378.

22. Mayilyan KR. Complement genetics, deficiencies, and disease associations. Protein Cell 2012; 3:487-496.

23. Macedo $A C$, Isaac $L$. Systemic lupus erythematosus and deficiencies of

- early components of the complement classical pathway. Front Immunol $2016 ; 7: 55$.

This article focuses on the deficiencies of early components of the complement system in SLE.

24. Lintner KE, Wu YL, Yang $\mathrm{Y}$, et al. Early components of the complement

- classical activation pathway in human systemic autoimmune diseases. Front Immunol 2016; 7:36.

This article investigates the therapeutic applications of targeting the complement

system in autoimmune diseases.

25. Ittiprasert W, Kantachuvesiri S, Pavasuthipaisit $\mathrm{K}$, et al. Complete deficiencies of complement C4A and C4B including 2-bp insertion in codon 1213 are genetic risk factors of systemic lupus erythematosus in Thai populations. J Autoimmun 2005; 25:77-84.

26. Mitchell DA, Pickering MC, Warren J, et al. C1q deficiency and autoimmunity: the effects of genetic background on disease expression. J Immunol 2002; 168:2538-2543.

27. Perricone R, Pasetto $N$, De Carolis $C$, et al. Functionally active complement is present in human ovarian follicular fluid and can be activated by seminal plasma. Clin Exp Immunol 1992; 89:154-157.

28. Triggianese $P$, Perricone $C$, Chimenti $M S$, et al. Innate immune system at the maternal-fetal interface: mechanisms of disease and targets of therapy in pregnancy syndromes. Am J Reprod Immunol 2016; 76:245-257.

29. Koucký M, Maličková $\mathrm{K}$, Kopřivová $\mathrm{H}$, et al. Low maternal serum concentra-

- tions of mannose-binding lectin are associated with the risk of shorter duration of pregnancy and lower birthweight. Scand J Immunol 2018; 88:e12675.

This study describes the strong association between complement component mannose-binding lectin and pregnancy outcome.

30. Cieslinski JZ, Goeldner I, Skare TL, et al. Mannose-binding lectin deficiency and miscarriages in rheumatoid arthritis. Autoimmunity 2017; 50:409-413.

31. Skare TL, Nisihara R, Cieslinski JZ, et al. Mannose-binding lectin deficiency in Brazilian patients with spondyloarthritis. Immunol Invest 2017; 46:183-189.

32. Kessel A, Peri R, Perricone $R$, et al. The autoreactivity of $B$ cells in hereditary angioedema due to $\mathrm{C} 1$ inhibitor deficiency. Clin Exp Immunol 2012; 167:422-428.

33. Farkas $H$, Csuka D, Gács J, et al. Lack of increased prevalence of immunoregulatory disorders in hereditary angioedema due to $\mathrm{C} 1$-inhibitor deficiency. Clin Immunol 2011; 141:58-66.

34. Varga L, Széplaki G, Visy B, et al. C1-inhibitor $(\mathrm{C} 1-\mathrm{INH})$ autoantibodies in hereditary angioedema: strong correlation with the severity of disease in $\mathrm{C} 1$ INH concentrate naïve patients. Mol Immunol 2007; 44:1454-1460.

35. Muhlemann MF, Macrae KD, Smith $A M$, et al. Hereditary angioedema and thyroid autoimmunity. J Clin Pathol 1987; 40:518-523.

36. Triggianese $P$, Guarino $M D$, Ballanti $E$, et al. Hereditary angioedema and autoimmunity. Isr Med Assoc J 2014; 16:622-624.

37. Reis SE, Falcão DA, Isaac L. Clinical aspects and molecular basis of primary deficiencies of complement component $\mathrm{C} 3$ and its regulatory proteins factor I and factor H. Scand J Immunol 2006; 63:155-168.

38. Omoyinmi E, Mohamoud I, Gilmour K, et al. Cutaneous vasculitis and digital ischaemia caused by heterozygous gain-of-function mutation in C3. Front Immunol 2018; 9:2524.

39. Szarvas N, Szilágyi Á, Csuka D, et al. Genetic analysis and functional characterization of novel mutations in a series of patients with atypical hemolytic uremic syndrome. Mol Immunol 2016; 71:10-22.
40. Parker CJ. Update on the diagnosis and management of paroxysmal nocturnal hemoglobinuria. Hematol Am Soc Hematol Educ Program 2016; 2016:208-216

41. Nanthapisal S, Eleftheriou D, Gilmour $K$, et al. Cutaneous vasculitis and recurrent infection caused by deficiency in complement factor I. Front Immunol 2018; 9:735

42. Chimenti MS, Ballanti E, Triggianese $P$, Perricone R. Vasculitides and the complement system: a comprehensive review. Clin Rev Allergy Immunol 2015; 49:333-346.

43. Rusai K, Zaller V, Szilagyi A, et al. A rare case: childhood-onset C3 glomerulonephritis due to homozygous factor $\mathrm{H}$ deficiency. CEN Case Rep 2013; 2:234-238.

44. Erdei A, Isaák A, Török K, et al. Expression and role of CR1 and CR2 on B and $T$ lymphocytes under physiological and autoimmune conditions. Mol Immunol 2009; 46:2767-2773.

45. Korb LC, Ahearn JM. C1q binds directly and specifically to surface blebs of apoptotic human keratinocytes: complement deficiency and systemic lupus erythematosus revisited. J Immunol 1997; 158:4525-4528.

46. Stokol T, O'Donnell $\mathrm{P}$, Xiao L, et al. C1q governs deposition of circulating immune complexes and leukocyte Fcgamma receptors mediate subsequent neutrophil recruitment. J Exp Med 2004; 200:835-846.

47. Bossi F, Tripodo C, Rizzi L, et al. C1q as a unique player in angiogenesis with therapeutic implication in wound healing. Proc Natl Acad Sci USA 2014; 111:4209-4214.

48. Botto M. Links between complement deficiency and apoptosis. Arthritis Res 2001; 3:207-210.

49. Chung SA, Taylor KE, Graham RR, et al. Differential genetic associations for systemic lupus erythematosus based on antidsDNA autoantibody production. PLoS Genet 2011; 7:e1001323.

50. Trendelenburg M. Antibodies against $\mathrm{C} 1 \mathrm{q}$ in patients with systemic lupus erythematosus. Springer Semin Immunopathol 2005; 27:276-285.

51. Yin $Y, W u X$, Shan $G$, et al. Diagnostic value of serum anti-C1q antibodies in patients with lupus nephritis: a meta-analysis. Lupus 2012; 21:1088-1097.

52. Wener MH, Mannik M, Schwartz MM, Lewis EJ. Relationship between renal pathology and the size of circulating immune complexes in patients with systemic lupus erythematosus. Medicine (Baltimore) 1987; 66:85-97.

53. Trendelenburg M, Marfurt J, Gerber I, et al. Lack of occurrence of severe lupus nephritis among anti-C1q autoantibody-negative patients. Arthritis Rheum 1999; 42:187-188.

54. Stojan G, Petri M. Anti-C1q in systemic lupus erythematosus. Lupus 2016; 25:873-877.

55. Marto N, Bertolaccini ML, Calabuig $\mathrm{E}$, et al. Anti-C1q antibodies in nephritis: correlation between titres and renal disease activity and positive predictive value in systemic lupus erythematosus. Ann Rheum Dis 2005; 64:444-448.

56. Moroni G, Trendelenburg M, Del Papa N, et al. Anti-C1 q antibodies may help in diagnosing a renal flare in lupus nephritis. Am J Kidney Dis 2001; 37:490-498.

57. Haddon DJ, Diep VK, Price JV, et al. Autoantigen microarrays reveal autoantibodies associated with proliferative nephritis and active disease in pediatric systemic lupus erythematosus. Arthritis Res Ther 2015; 17:162.

58. Conigliaro $\mathrm{P}$, Cesareo $\mathrm{M}$, Chimenti MS, et al. Take a look the eyes in systemic lupus erythematosus: a novel point of view. Autoimmun Rev 2019; 18:247-254

59. Conigliaro $\mathrm{P}$, Cesareo $\mathrm{M}$, Chimenti MS, et al. Evaluation of retinal microvascular density in patients affected by systemic lupus erythematosus: an optical coherence tomography angiography study. Ann Rheum Dis 2019; 78:287-289.

60. Conigliaro $P$, Triggianese $P$, Draghessi $G$, et al. Evidence for the Detection of Subclinical Retinal Involvement in systemic lupus erythematosus and Sjögren syndrome: a potential association with therapies. Int Arch Allergy Immunol 2018; 177:45-56.

61. Conigliaro $\mathrm{P}$, Cesareo $\mathrm{M}$, Chimenti MS, et al. Response to: 'OCTA, a sensitive screening for asymptomatic retinopathy, raises alarm over systemic involvements in patients with SLE' by Mizuno et al. Ann Rheum Dis 2018; pii: annrheumdis-2018-214796.

62. Patakas A, Benson RA, Withers DR, et al. Th17 effector cells support B cell responses outside of germinal centres. PLoS One 2012; 7:e49715.

63. Prechl J, Papp K, Hérincs Z, et al. Serological and genetic evidence for - altered complement system functionality in systemic lupus erythematosus: findings of the GAPAID consortium. PLoS One 2016; 11 :e0150685.

This study demonstrates a dysfunction of the receptor recognizing complement promoting the development of class-switched autoantibodies targeting nucleic acids.

64. Berden $\mathrm{JH}$, Licht $\mathrm{R}$, van Bruggen $\mathrm{MC}$, et al. Role of nucleosomes for induction and glomerular binding of autoantibodies in lupus nephritis. Curr Opin Nephrol Hypertens 1999; 8:299-306.

65. Truedsson L, Bengtsson AA, Sturfelt G. Complement deficiencies and systemic lupus erythematosus. Autoimmunity 2007; 40:560-566.

66. Cacoub P, Frémeaux-Bacchi V, De Lacroix I, et al. A new type of acquired C1 inhibitor deficiency associated with systemic lupus erythematosus. Arthritis Rheum 2001; 44:1836-1840.

67. Cugno M, Castelli R, Cicardi M. Angioedema due to acquired C1-inhibitor deficiency: a bridging condition between autoimmunity and lymphoproliferation. Autoimmun Rev 2008; 8:156-159. 
68. Chen M, Jayne DR, Zhao MH. Complement in ANCA-associated vasculitis: -1. mechanisms and implications for management. Nat Rev Nephrol 2017; 13:359-367.

This article describes evidence of the role of complement system in ANCAassociated vasculitis.

69. Camous L, Roumenina L, Bigot S, et al. Complement alternative pathway acts as a positive feedback amplification of neutrophil activation. Blood 2011; 117:1340-1349.

70. Haas M, Eustace JA. Immune complex deposits in ANCA-associated crescentic glomerulonephritis: a study of 126 cases. Kidney Int 2004; 65: 2145-2152.

71. $\mathrm{Yu} F$, Chen M, Gao $\mathrm{Y}$, et al. Clinical and pathological features of renal involvement in propylthiouracil-associated ANCA-positive vasculitis. Am J Kidney Dis 2007; 49:607-614.

72. Xing GQ, Chen M, Liu G, et al. Complement activation is involved in renal damage in human antineutrophil cytoplasmic autoantibody associated pauciimmune vasculitis. J Clin Immunol 2009; 29:282-291.

73. Hilhorst $\mathrm{M}$, van Paassen $\mathrm{P}$, van Rie $\mathrm{H}$, et al. Complement in ANCA-associated glomerulonephritis. Nephrol Dial Transplant 2017; 32:1302-1313.

74. Yuan J, Gou SJ, Huang J, et al. C5a and its receptors in human antineutrophil cytoplasmic antibody (ANCA)-associated vasculitis. Arthritis Res Ther 2012; 14:R140.

75. Gou SJ, Yuan J, Wang C, et al. Alternative complement pathway activation products in urine and kidneys of patients with ANCA-associated GN. Clin J Am Soc Nephrol 2013; 8:1884-1891.

76. Xiao H, Heeringa P, Hu P. Antineutrophil cytoplasmic autoantibodies specific for myeloperoxidase cause glomerulonephritis and vasculitis in mice. J Clin Invest 2002; 110:955-963.

77. Huugen $\mathrm{D}$, van Esch $\mathrm{A}, \mathrm{Xiao} \mathrm{H}$, et al. Inhibition of complement factor $\mathrm{C5}$ protects against antimyeloperoxidase antibody-mediated glomerulonephritis in mice. Kidney Int 2007; 71:646-654.

78. Wang $\mathrm{Y}, \mathrm{Hu} \mathrm{Q}$, Madri JA, et al. Amelioration of lupus-like autoimmune disease in NZB/WF1 mice after treatment with a blocking monoclonal antibody specific for complement component C5. Proc Natl Acad Sci USA 1996; 93:8563-8568.

79. Sciascia S, Radin M, Yazdany J, et al. Expanding the therapeutic options for renal involvement in lupus: eculizumab, available evidence. Rheumatol Int 2017; 37:1249-1255.

80. Kello N, Khoury LE, Marder G, et al. Secondary thrombotic microangiopathy in systemic lupus erythematosus and antiphospholipid syndrome, the role of complement and use of eculizumab: case series and review of literature. Semin Arthritis Rheum 2018. pii: S0049-0172(18)30493-1.

81. Hillmen $P$, Hall $C$, Marsh JC, et al. Effect of eculizumab on hemolysis and transfusion requirements in patients with paroxysmal nocturnal hemoglobinuria. N Engl J Med 2004; 350:552-559.

82. Hillmen $P$, Young NS, Schubert $J$, et al. The complement inhibitor eculizumab in paroxysmal nocturnal hemoglobinuria. N Engl J Med 2006; 355: $1233-1243$.

83. Legendre CM, Licht $\mathrm{C}$, Muus $\mathrm{P}$, et al. Terminal complement inhibitor eculizumab in atypical hemolytic-uremic syndrome. N Engl J Med 2013; 368:2169-2181.

84. Vivarelli M, Emma F. Treatment of $\mathrm{C} 3$ glomerulopathy with complement blockers. Semin Thromb Hemost 2014; 40:472-477.
85. Rosenblad T, Rebetz J, Johansson M, et al. Eculizumab treatment for rescue of renal function in IgA nephropathy. Pediatr Nephrol 2014; 29:2225-2228.

86. Pickering $M C$, Ismajli $M$, Condon $M B$, et al. Eculizumab as rescue therapy in severe resistant lupus nephritis. Rheumatology (Oxford) 2015; 54:2286-2288

87. Danza A, Ruiz-Irastorza G. Infection risk in systemic lupus erythematosus patients: susceptibility factors and preventive strategies. Lupus 2013; 22:1286-1294.

88. Manzi S, Kuller LH, Kutzer J, et al. Herpes zoster in systemic lupus erythematosus. J Rheumatol 1995; 22:1254-1258.

89. Alarcon GS. Infections in systemic connective tissue diseases: systemic lupus erythematosus, scleroderma, and polymyositis/dermatomyositis. Infect Dis Clin North Am 2006; 20:849-875.

90. Nath R, Mant C, Luxton J, et al. High risk of human papillomavirus type 16 infections and of development of cervical squamous intraepithelial lesions in systemic lupus erythematosus patients. Arthritis Rheum 2007; 57:619-625.

91. Doaty $S$, Agrawal H, Bauer E, Furst DE. Infection and lupus: which causes which? Curr Rheumatol Rep 2016; 18:13.

92. Feldman $\mathrm{CH}$, Hiraki LT, Winkelmayer WC, et al. Serious infections among adult Medicaid beneficiaries with systemic lupus erythematosus and lupus nephritis. Arthritis Rheumatol 2015; 67:1577-1585.

93. Lee YH, Choi SJ, Ji JD, Song GG. Overall and cause-specific mortality in systemic lupus erythematosus: an updated meta-analysis. Lupus 2016; 25:727-734.

94. Marquart HV, Svendsen A, Rasmussen JM, et al. Complement receptor expression and activation of the complement cascade on B lymphocytes from patients with systemic lupus erythematosus (SLE). Clin Exp Immunol 1995; 101:60-65.

95. Gao J, Zhang L, Zhang X, et al. Levels of serum procalcitonin and C-reactive protein for evaluating pulmonary bacterial infection in patients with lupus erythematosus. J Huazhong Univ Sci Technolog Med Sci 2016; 36:653-658

96. Echeverri A, Naranjoescobar J, Possoosorio I, et al. Neutrophil CD64

- expression, procalcitonin and presepsin are useful to differentiate infections from flares in SLE patients with SIRS. Lupus 2018; 27:1130-1139.

This study evaluates the usefulness of a number of biomarkers for differentiating infections from activity in SLE patients.

97. Feng $M$, Zhang SL, Liang ZJ, et al. Peripheral neutrophil CD64 index combined with complement, CRP, WBC count and B cells improves the ability of diagnosing bacterial infection in SLE. Lupus 2019; 28: 304-316.

98. Trouw LA, Pickering MC, Blom AM. The complement system as a potential I. therapeutic target in rheumatic disease. Nat Rev Rheumatol 2017; 13:538-547.

This comprehensive review evaluates the therapeutic potential of complement manipulation in rheumatology.

99. Chimenti MS, Perricone C, Graceffa D, et al. Complement system in psoriatic arthritis: a useful marker in response prediction and monitoring of anti-TNF treatment. Clin Exp Rheumatol 2012; 30:23-30.

100. Di Muzio G, Perricone C, Ballanti E, et al. Complement system and rheumatoid arthritis: relationships with autoantibodies, serological, clinical features, and anti-TNF treatment. Int J Immunopathol Pharmacol 2011; $24: 357-366$ 